\title{
Influence of pricing on mode choice decision in Jakarta A random regret minimization model
}

\section{Working Paper}

Author(s):

Belgiawan, Prawira F.; Ilahi, Anugrah; Axhausen, Kay W. (D)

Publication date:

2017

Permanent link:

https://doi.org/10.3929/ethz-b-000175255

Rights / license:

$\underline{\text { In Copyright - Non-Commercial Use Permitted }}$

Originally published in:

Arbeitsberichte Verkehrs- und Raumplanung 1268 


\section{Influence of Pricing on Mode Choice Decision in Jakarta: A Random Regret Minimization} Model

\section{Prawira Fajarindra Belgiawan, Corresponding Author}

Institute for Transport Planning and System (IVT), ETH Zürich, Switzerland

HIL, F51.1, Stefano-Franscini-Platz 58093 Zürich Switzerland

Tel: +41 4463333 25; Email: fajarindra.belgiawan@ivt.baug.ethz.ch

\section{Anugrah Ilahi}

12 Institute for Transport Planning and System (IVT), ETH Zürich, Switzerland

13 HIL, F31.2, Stefano-Franscini-Platz 58093 Zürich Switzerland

14 Tel: +41 4463331 05; Email: anugrah.ilahi@,ivt.baug.ethz.ch

\section{Kay W. Axhausen}

17 Institute for Transport Planning and System (IVT), ETH Zürich, Switzerland

18 HIL, F31.3, Stefano-Franscini-Platz 58093 Zürich Switzerland

19 Tel: +41 4463339 43; Email: axhausen@,ivt.baug.ethz.ch

23 Word count: 5,835 words text +6 tables/figures x 250 words (each) $=7,335$ words 
1 ABSTRACT

2 To reduce traffic congestion, the Government of Jakarta is planning to implement electronic road 3 pricing (ERP) for commuters who pass through arterial roads in Jakarta's CBD area. This paper 4 studies the implementation of ERP, which in this study is called contribution cost, by utilizing the 5 recently introduced alternative choice model approach called random regret minimization (RRM). 6 In RRM when deciding, an individual is assumed to minimize anticipated regret as opposed to 7 maximizing the utility. A stated preference (SP) survey has been conducted with 507 respondents. 8 Four alternative modes (public transport, park and ride, car, and motorcycle) were presented with 9 several attributes such as travel time, travel cost, waiting time, transfer, parking cost, and 10 contribution cost. The SP survey was divided into two parts, Model 1 with all attributes including 11 contribution cost, and Model 2 with only travel time and travel cost (without the contribution costs). 12 In total 6003 observations for 12 scenarios in Model 1, and 4011 observations for 8 scenarios in 13 Model 2 were obtained. Comparing model fit and prediction accuracy, Model 2 outperforms Model 14 1. Regarding the value of travel time savings (VTTS), it appears that the incorporation of 15 contribution cost (and other attributes) results in substantially higher VTTS for Model 1 compared 16 to Model 2. Finally for demand elasticities are larger than one for public transport, park and ride 17 and car travel time. The results also show that car contribution cost elasticity is substantially higher 18 than motorcycle contribution cost elasticity. 


\section{INTRODUCTION}

2 Traffic congestion is becoming a global issue recently. Increasing numbers of private vehicle and 3 a lack of sufficient investment in public transport infrastructure are the main problems faced by Indonesia particularly Jakarta City (1). In 2003, Jakarta Government implemented a 3 in 1 highoccupancy vehicle (HOV) policy on several arterial roads in Jakarta CBD for private vehicles (2). In a 3 in 1 policy, private cars with less than three persons are not allowed to travel on arterial roads during morning and evening peak hours. Unfortunately, this policy has not been successful in improving urban transport conditions due to lack of control and some further implementation issues. For example, many people pay brokers to fulfill the minimum number of passengers (3). This led to the revocation of this policy (4).

Due to the failures of this policy, there is a movement to replace the 3 in 1 scheme with more comprehensive approach such as Electronic Road Pricing (ERP). It is argued that for the case of Jakarta ERP will produce financial resources for other projects (5). ERP has already been successfully implemented in several countries $(5 ; 6 ; 7 ; 8)$. For example, Singapore has succeeded to shift private car users to use public transport by $10 \%$ to $20 \%$ (5). The ALS (Area Licensing Scheme) in London has significantly reduced the number of private vehicles (6). Other examples include Milan (7) and Stockholm (8). Several studies have already been conducted on the feasibility of ERP in Jakarta. Prayudyanto et al. (9) evaluated several approaches that can support the implementation of congestion charging. Sugiarto et al. $(11 ; 12)$ have explored the psychological factors that influence the public acceptance of ERP schemes. Their results emphasize that clear introduction and explanation of the benefits of the ERP policy might increase public acceptance of its implementation.

Following their findings, this paper contributes to evaluating the potential of ERP implementation in Jakarta by estimating the impact of ERP on mode choice in Jakarta. Another contribution of this paper is the application of recently introduced alternative modeling approach called random regret minimization (RRM) to the study of the impact of ERP policy adoption. RRM is an alternative modeling technique which in contrast to utility maximization (RUM) minimizes anticipated regret (13). Similar to RUM studies, a stated choice (SP) experiment has been conducted in order to collect the data. It is important to explain clearly to the respondents the benefit of ERP to increase public acceptance. Thus the respondents are told prior the survey that the ERP will contribute to for example improving public transport, building new infrastructure, financing transport services, etc. Since the emphasis is in the "contribution," in this research the term ERP or congestion charging is replaced by "contribution cost," in order to avoid any negative perception during the survey and present the positive message that the respondents will contribute to improving the present public transport system. In this paper, not only the model estimates are presented but also other indicators such as the value of travel time savings and demand elasticities.

The remainder of this paper is structured as follows. The next section presents the history of RRM and its theoretical application. This section is followed by the description of survey design and data collection followed by the descriptive analysis of the data. The section following that presents modeling application results of VTTS indicators and demand elasticities. Finally, the last section offers conclusions and further recommendations.

\section{2 \\ RANDOM REGRET MINIMIZATION}

Recently a new alternative to random utility maximization (RUM) is gaining more attention. This new alternative modeling approach is called random regret minimization (RRM). Chorus et al. (14) first introduced RRM for a model of travel choice. In RRM, an individual chooses an alternative from sets of available alternatives wishing to avoid a situation where a chosen 
alternative turns out to be less attractive than other non-chosen alternatives, which causes regret. As a result, the individual is assumed to minimize anticipated regret as opposed to maximizing her/his utility when deciding. According to Chorus (13), the earlier version of RRM (14) has two limitations, therefore to alleviate those limitations, Chorus (13) proposed a new RRM-approach. In the RRM framework, the regret associated with alternative $i$ is obtained by formula in Eq.1 (13).

$$
R R_{i q}=R_{i q}+\varepsilon_{i q}=\delta_{i}+\sum_{j \neq i} \sum_{m} \ln \left(1+\exp \left[\beta_{m} \cdot\left(\chi_{m j q}-\chi_{m i q}\right)\right]\right)+\varepsilon_{i q}
$$

where, $R R_{i q} \quad$ : random (or total) regret for an alternative $i$ for person $q$

$R_{i q} \quad$ : systematic regret for an alternative $i$ for person $q$

$\varepsilon_{i q} \quad$ : unobserved regret for an alternative $i$ for person $q$

$\delta_{i} \quad$ : alternative specific constant

$\beta_{m} \quad$ : parameter associated with attribute $\chi_{m}$

$\chi_{m i q}, \chi_{m i q}:$ values associated with an attribute $\chi_{m}$ for, respectively, person $q$ choosing alternative $i$ over alternative $j$.

The RRM framework assumes the error term in Eq. 1 be identically and independently distributed (i.i.d) Extreme Value Type I-distributed with a variance of $\pi^{2} / 6$. In the RRM setting, the formulation of choice probabilities is as follow (13):

$$
P_{i q}=\frac{\exp \left(-R_{i q}\right)}{\sum_{j=1 . \ldots J} \exp \left(-R_{j q}\right)}
$$

There have been many studies utilized RRM for transportation related choice decision. For example, route choice, shopping location, travel information acquisition choice, parking lot (14; 15), mode choice (16), automobile fuel choice (17), willingness to pay for advanced transportation services, and salary and travel time trade off (18). Chorus et al. (19) discussed about 43 empirical studies that compare RUM and RRM from 2010-2014. Regarding their model fit, 15 times RRM outperforms RUM and 15 times the other way around. Other 13 empirical studies show neither of these two modeling approaches outperforms each other. Adding to that list is the study by Belgiawan et al. (16) where they compare the performance of RUM and RRM on seven Swiss data sets. They found that RRM outperforms RUM in six cases.

Note that most empirical studies compared RUM and RRM regarding their model fit. Few exceptions discussed the application of the model such as the value of travel time savings (VTTS), and demand elasticities. For example, Leong and Hensher (20) compare the VTTS from the results of RUM and RRM and found that there is a statistically significant difference between RUM and RRM for seven route choice data sets from Australia and New Zealand. Regarding demand elasticities, Chorus and Bierlaire (21) reported that travel time elasticities of the RRM model are nearly $10 \%$ greater compared to RUM for the case of route choice. Similarly, for a route choice case, Thiene et al. (22) found that RRM model elasticities were about $10 \%$ greater than the RUM model. For the case of alternative fuel car use, Hensher et al. (17) found a substantial difference in the elasticities between RUM and RRM, which the RRM is higher than RUM.

To date, there are several variants of RRM and other context-dependent models. The first 
one is called generalized RRM (23). This model generalizes the RRM by replacing the one parameter inside the logarithmic function with a regret-weight parameter. The second variant is called $\mu \mathrm{RRM}(24)$. In this type, a scale parameter $(\mu)$ is incorporated in the model as an additional degree of freedom which allow for flexibility of the regret function level attribute. The final RRM variant is called pure-RRM (24). Pure RRM (PRRM) yields the strongest regret minimization behavior since this model postulates no rejoice experienced as oppose to regret. Another contextdependent model introduced is called relative advantage maximization (RAM) (20). RAM compares the chosen alternative with the competing alternative similar to RRM. The difference between RAM and RRM is that RAM explicitly takes into account the relative difference between the advantage (rejoice) and the disadvantages (regret) of an alternative. There are not many discussion about the application of those approaches; only some studies discuss the comparison of those approaches and RUM $(16 ; 20 ; 23 ; 24)$. However, there are now many studies comparing the performance of RUM and RRM, and as mentioned above with some pointing out that RRM outperforms RUM in term of model fit, and giving different VTTS and demand elasticities.

Since many studies have shown that RRM is an established alternative to RUM, this paper does not compare the performance of RUM and RRM. This research utilized RRM as an alternative of RUM to study the impact of contribution cost on mode choice decision in Jakarta. To the authors' knowledge, this is the first study to utilize RRM for mode choice decision in Jakarta area. Another reason to implement RRM is that paying for contribution cost for private vehicle might lead to a regret of choosing an alternative for example car or motorcycle in comparison to choosing a public transport.

\section{DATAAND DESCRIPTIVE ANALYSIS}

\section{Survey Design and Data Collection}

The survey was designed to understand the respondents' mode choice preference if the government were to implement contribution cost on some arterial roads in Jakarta's CBD. The respondents received an explanation that the contribution cost will be used by the government to build infrastructures and to improve the performance and quality of public transport system in Jakarta. The respondents are those who live in Jakarta and pass through those arterial roads for their daily acitivities. Since the discussion is about arterial roads, note that non-motorized alternative modes such as walk and bicycle are not included in the survey. There are four alternative modes in this study that mostly pass through arterial roads in Jakarta: public transport (PT), park and ride, car, and motorcycle. The respondents were informed that public transport refers to all regular public transport services such as TransJakarta (Jakarta Bus Rapid Transit), commuter rail, regular bus, and mini-bus. The respondents were also told that park and ride refers to the usage of private vehicle to a PT terminal and park their vehicle there before continuing the trip using PT. In 2011, the Jakarta Government have provided five park and ride facilities and they are planning to provide 19 more facilities to support commuting activities in Jakarta Greater Area (25).

The questionnaire is divided into three parts; the first part is the stated preference (SP) survey which asked about 12 sets of labeled choice experiments with full sets of the attributes including travel time, travel cost, waiting time to board the first PT vehicle, number of transfer, contribution cost and parking cost. The second part is a further SP survey, with eight sets of labeled choices set which only contain travel time, and travel cost as attributes. Travel cost for both questionnaire parts refers to the ticket cost for PT and the fuel cost for car/motorcycle. With this division, the VTTS with or without contribution cost as well as finding the influence of contribution cost on mode choice decision can be compared. The third part of the questionnaire 


\begin{tabular}{|l|r|r|r|r|}
\hline Attribute & Public Transport & Park and Ride & \multicolumn{1}{l|}{ Car } & \multicolumn{1}{l|}{ Motorcycle } \\
\hline Travel time (minute)* & $30,45,60,75$ & $30,45,60,75$ & $30,45,60,75$ & $20,30,40,60$ \\
\hline Travel cost (IDR 1k)* & $4,8,12,16,20$ & $8,12,16,20,25$ & $12,16,18,20,25$ & $4,8,12,16$ \\
\hline Waiting time (minute) & $10,15,20,25$ & $10,15,20,25$ & 0 & 0 \\
\hline Transfer & $0,1,2,3$ & $1,2,3$ & 0 & 0 \\
\hline Contribution cost (IDR 1k) & 0 & 0 & $10,15,20,25$ & $5,8,10,12$ \\
\hline Parking cost (IDR 1k) & 0 & 4,6 & 5,10 & $2,4,6$ \\
\hline
\end{tabular}

asked the respondents about their socio-demographic characteristics such as age, gender, and income.

The experimental designs were developed by Ngene with D-efficient design. Size of choice sets depends on the number of attributes. For instance, there are 36 sets of choice experiments divided into three blocks in part 1 , which each respondent receives 12 sets of choice experiment. Moreover, part 2 contains 24 sets of choice experiments divided into three blocks, which each respondent receives 8 sets of choice experiment. Each experiment contains different values of the variables. The value of variable is presented in Table 1 .

\section{TABLE 1 Attributes and their values in SP experiments}

The data were collected using ETH Zurich online survey tools (www.selectsurvey.ethz.ch).

\section{Descriptive Analysis}

Table 2 illustrates sociodemographic characteristics of the respondents. The majority of respondents are below 39 years old with 25-39 years old being the highest proportion. The male respondents are slightly more represented than female respondents with a share of $54.04 \%$. Regarding income level, the 2017 provincial minimum wage issued by the government is IDR $3,355,750$ per month (26). Still about $13.60 \%$ earn less. The highest proportion is those who are in the top category.

In the right column, gender and age proportion of 9,607,787 Jakarta inhabitants from the 2010 population census (27) are presented. Since the proportion of age category of the sample is not similar to the population proportion, the weight calculation are performed using "post-stratified weights." The weight calculation, by age and gender, is necessary to calculate the aggregate direct point elasticities. 
TABLE 2 Respondents Characteristics

\begin{tabular}{|l|l|r|r|}
\hline Variable & Value & Sample & \\
\hline \multirow{4}{*}{ Gender } & Male & $54.04 \%$ & Population \\
\cline { 2 - 4 } & Female & $45.96 \%$ & $50.70 \%$ \\
\hline \multirow{5}{*}{$\begin{array}{l}\text { Income } \\
\text { in IDR per month*) }\end{array}$} & $1-24$ & $44.58 \%$ & $49.30 \%$ \\
\cline { 2 - 4 } & $25-39$ & $45.56 \%$ & $42.92 \%$ \\
\cline { 2 - 4 } & $40-54$ & $7.89 \%$ & $30.95 \%$ \\
\cline { 2 - 4 } & $55-65$ & $1.38 \%$ & $17.71 \%$ \\
\cline { 2 - 4 } & $66+$ & $0.59 \%$ & $4.01 \%$ \\
\cline { 2 - 4 } & No answer & $1.38 \%$ & $4.40 \%$ \\
\cline { 2 - 4 } & Less than IDR 1,000 K & $1.38 \%$ & $\mathrm{NA}$ \\
\cline { 2 - 4 } & IDR 1,000 K - 2,000 K & $5.72 \%$ & $\mathrm{NA}$ \\
\cline { 2 - 4 } & IDR 2,000 K - 6,000 K & $27.02 \%$ & $\mathrm{NA}$ \\
\cline { 2 - 4 } & IDR 6,000 K - 10,000 K & $19.33 \%$ & $\mathrm{NA}$ \\
\cline { 2 - 4 } & More than IDR 10,000 K & $45.17 \%$ & $\mathrm{NA}$ \\
\hline
\end{tabular}

\section{MODEL ESTIMATION}

In accordance with the two parts of the questionnaire, there are two models estimated in this paper. The first model incorporates all attributes in Table 1 including contribution cost. The second model only incorporates two attributes, travel time and travel cost. These two models give better idea of incorporating contribution cost or not in the mode choice model. The estimation method is maximum likelihood estimation with PythonBiogeme (28). The result can be found in Table 3.

The interpretation of parameter estimates in RRM context is different than RUM. In RUM context, for example, multinomial logit model (MNL), a parameter estimate refers to increase or decrease in the utility of an alternative caused by a one-unit increase or decrease in an attribute's value. Whereas in RRM context, a parameter estimate refers to the potential increase or decrease in regret associated with comparing a considered alternative with the competing alternative in term of one unit increase in an attribute's value. To confirm whether an attribute is important for the choice probability, the direct elasticities needs to be calculated (in the next section).

For all models, the parameter estimates are significant with the expected sign (negative) except for parking cost. The insignificant result of parking cost parameter is quite surprising since other study, for example, in Swiss context which incorporate similar attributes found that parking cost is significant (29). There are three possible reasons for this. The first one might be due to people can park anywhere on the street (on-street parking), and there is no strict regulation to prohibit them in doing so especially in the street where there is no "no parking" sign (30). Moreover, people can buy a car even though they do not have sufficient parking space. For example, those who do not have parking space in their house can park their car on the street in front of their house without any payment. Another reason might be because parking price itself is quite low especially for on-street parking. Officially, people pay the parking price to the government. However there are also some illegal parking and also unreported parking (31).

Table 3 also presents alternative specific constant (ASC) for each mode. For identification the car ASC is set to zero. In RRM context, the positive and significant value of ASC increases the regret of choosing that alternative compared to the competing base alternative. Therefore, ceteris paribus, that mode is less preferred compared to the competing alternative. In model 1, ASC public transport is not significant, that means public transport is not more or less preferred compare to car. ASC motorcycle positive significant at $10 \%$, which means motorcycle might be less preferred compared to car. Park and ride is positive significant indicating that it is less preferred than car. 
This is interesting since, with the presence of contribution cost, car is still more preferred. Another possibility might be due to the respondents are not familiar with the term "park and ride." For 3 model 2, with only travel time and cost, there is only one significant difference in ASC. Motorcycle 4 is less preferred compared to car.

TABLE 3 Model Estimation

\begin{tabular}{|c|c|c|c|c|}
\hline \multirow{2}{*}{ Variables } & \multicolumn{2}{|c|}{ Model 1 - With contribution cost } & \multicolumn{2}{|c|}{ Model 2 - Without contribution cost } \\
\hline & Estimation & t-test & Estimation & t-test \\
\hline \multicolumn{5}{|l|}{ Model Estimation } \\
\hline Travel time & -0.021 & -32.44 & -0.037 & -14.45 \\
\hline Travel cost & -0.015 & -8.17 & -0.028 & -30.21 \\
\hline Waiting time & -0.007 & -3.37 & NA & NA \\
\hline Transfer & -0.061 & -3.90 & NA & NA \\
\hline Contribution cost & -0.015 & -5.63 & NA & NA \\
\hline Parking cost & -0.007 & $-1.24 *$ & NA & NA \\
\hline ASC public transport & -0.171 & $-1.07 *$ & -0.079 & $-1.31 *$ \\
\hline ASC park and ride & 0.275 & 2.07 & 0.004 & $0.06^{*}$ \\
\hline ASC motorcycle & 0.142 & $1.82 * *$ & 0.154 & 2.64 \\
\hline \multicolumn{5}{|l|}{ Model fit } \\
\hline Observations & & 6003 & & 4011 \\
\hline Final-LL & & -6978.398 & & -4027.988 \\
\hline Rho-square & & 0.161 & & 0.276 \\
\hline AIC & & 2.33 & & 2.01 \\
\hline BIC & & 2.34 & & 2.02 \\
\hline \multicolumn{5}{|l|}{ Prediction Accuracy } \\
\hline Hit rate ( $100 \%$ sample) & & $50.26 \%$ & & $63.95 \%$ \\
\hline Out of sample hit rate & & $50.01 \%$ & & $63.01 \%$ \\
\hline
\end{tabular}

Since the number of parameter and observations are different, perhaps the final-LL and AIC can not be compared. However Rho-square and BIC can be compared. Looking at rho-square and BIC it appears that fewer attributes give better model fit in this context. This might indicate that the parsimonious model is sufficient for Jakarta case.

At the bottom of the table, hit rate and out of sample hit rate are presented. Hit rate refers to the fit between actual choice observed in the data and the predicted choice obtained from the 12 model result. The higher percentage of hit rate shows how close the model in representing reality. 13 To do a validation, out of sample hit rate was performed. The data was divided into two part, the 14 first part (2/3) of the data was used for estimation, and then the estimation result was used to 15 simulate the probability using the other part (1/3) of the data. For validation, the was repeated five 16 times and the average hit rates are presented at the bottom of Table 3 . The hit rate (and its 17 validation) are higher for the parsimonious model. 


\section{MODEL APPLICATION}

\section{Value of Travel Time Savings}

The value of travel time savings (VTTS) is an important factor for a transportation infrastructure project. It measures amount of money (e.g. an individual is willing to pay for a reduction of a unit of travel time (e.g. hour). In discrete choice model, especially RUM context, the VTTS is obtained by dividing travel time parameter and travel cost parameter (32). For RRM context, the formula to measure VTTS, as also shown in Chorus (13) can be seen in Eq. 3.

$V T T S_{i q}=60 \times \frac{\partial R_{i q} / \partial T T_{i q}}{\partial R_{i q} / \partial T C_{i q}}=60 \times \frac{\sum_{j \neq i}-\beta_{T T}\left(\exp \left[-\beta_{T T} \cdot\left(T T_{j q}-T T_{i q}\right)\right]+1\right)}{\sum_{j \neq i}-\beta_{T C} /\left(\exp \left[-\beta_{T C} \cdot\left(T C_{j q}-T C_{i q}\right)\right]+1\right)}$

where $R_{i q}$ represents systematic regret for alternative $i$ for person $q, T T_{j q}-T T_{i q}$ represents travel time for the person $q$ choosing an alternative $i$ over competing alternative $j$, and $T C_{j q}-T C_{i q}$ represent the travel cost for the person $q$ choosing an alternative $i$ over competing alternative $j$. While $\beta_{T T}$ and $\beta_{T C}$ represent the parameters of travel time and travel cost respectively. The derivation of the formula to measure VTTS for RRM is included in Belgiawan et al. (16).

RRM is a context-dependent model. It means the performance of other a chosen alternative is also influenced by the performance of other non-chosen alternatives. Therefore, as shown in in Eq.3, VTTS measures will change when the number of available alternatives is changed in the choice set. Changes in the attributes, for example, travel time of competing alternatives will also change the VTTS.

The formula to measure the value of contribution cost per hour $(\mathrm{CCH})$ is shown in Eq.4.

$$
C C H_{i q}=60 \times \frac{\partial R_{i q} / \partial T T_{i q}}{\partial R_{i q} / \partial C C_{i q}}=60 \times \frac{\sum_{j \neq i}-\beta_{T T} /\left(\exp \left[-\beta_{T T} \cdot\left(T T_{j q}-T T_{i q}\right)\right]+1\right)}{\sum_{j \neq i}-\beta_{C C} /\left(\exp \left[-\beta_{T C} \cdot\left(C C_{j q}-C C_{i q}\right)\right]+1\right)}
$$

where $C C_{j q}-C C_{i q}$ represents contribution cost for the person $q$ choosing an alternative $i$ over competing alternative $j$, and $\beta_{C C}$ represent the parameters of contribution cost.

The mean value of travel time savings for two models and also contribution cost for the first model are presented in Table 4. In the RUM context, higher VTTS can be interpreted as individual is willing to pay more in order to gain time in the respected mode. In the RRM context, the interpretation would be that individual is willing to pay more in order to gain time in the mode considered relative to the performance of other competing modes. Higher VTTS for RRM context might also be interpreted as the more individual is willing to pay to minimize regret experienced by choosing that respective mode. It is interesting that the VTTS of public transport is the highest compared to other modes.

The comparison of these two models show that incorporating contribution cost (and also other attributes) increase the willingness to pay to minimize regret in the respected mode. However, the addition of contribution cost does not change the rank of VTTS for four modes, public transport is the highest, followed by park and ride, car, and motorcycle. It can also be interpreted that with the addition of contribution cost, the preference to choose an alternative does not change, which means individuals still prefer to use car and motorcycle. 
TABLE 4 Value of Travel Time Savings

\begin{tabular}{|l|r|r|r|r|}
\hline \multicolumn{9}{|c|}{} & Public transport & Park and ride & Car & Motorcycle \\
\hline Model 1 & 91,180 & 85,523 & 82,704 & 74,879 \\
\hline $\begin{array}{l}\text { Value of travel time savings } \\
\text { (IDR/hour) }\end{array}$ & 97,380 & 98,288 & 80,283 & 72,701 \\
\hline Contribution cost per hour (IDR/hour) & 50,250 & 45,444 & 44,609 & 38,677 \\
\hline Model 2
\end{tabular}

Based on the 2017 provincial minimum wage, the minimum hourly wage for Jakarta is calculated. It is approximately IDR 20,000. It appears that the average VTTS even for Model 2 motorcycle is higher than the minimum hourly wage. The average hourly wage for 507 samples is approximately IDR 70,000. It is higher than average VTTS for all modes in Model 2 but it is slightly lower than motorcycle VTTS in Model 1.

In order to provide a better depiction of the VTTSs and contribution cost distribution, they are plotted by alternative modes in Figure 1. At the x-axis, this paper presents the alternatives modes and at the y-axis, the VTTS in IDR 1,000 per hour is presented.

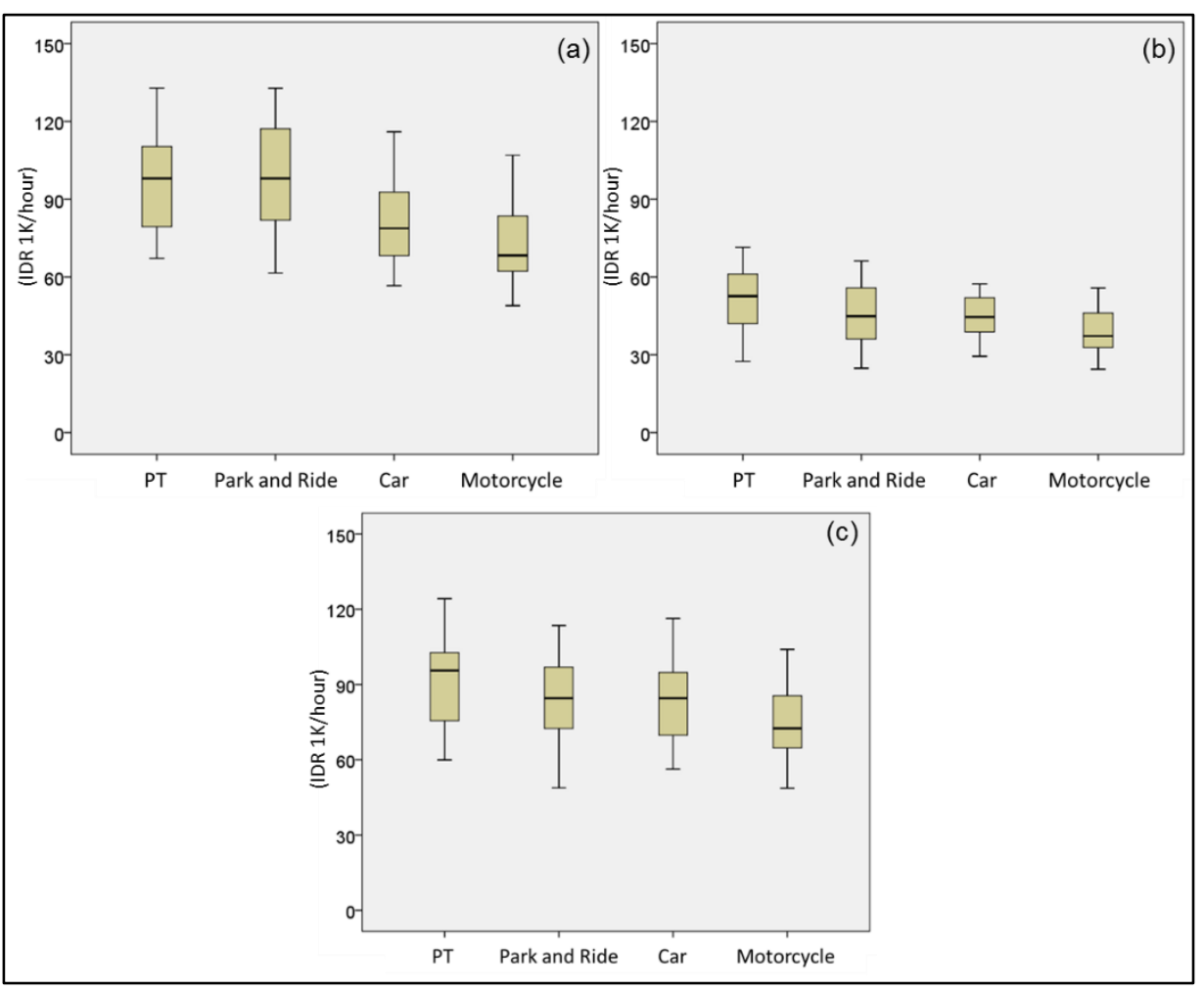

11 FIGURE 1 (a) VTTS Model 1; (b) VTTS Model 2; (c) Contribution Cost Model 1.

\section{Demand Elasticities}

13 As mentioned before, parameter estimate in RRM context does not translate to the importance of 14 a particular attribute as a determinant of choice behavior. Therefore, in order to find the importance 15 of an attribute, it is necessary to measure the direct point elasticities. Direct point elasticity shows 
the relationship between percentage changes in the magnitude of the attribute of alternative $i$ on the choice probability of alternative $i$.

Hensher et al. (17) and also Belgiawan et al. (16) derived an equation to measure the disaggregate direct point elasticity of RRM $\left(E_{i q \chi_{\text {miq }}}\right)$ as shown in Eq. 5.

$\left.\left.E_{i q \chi_{m i q}}=\left(\left(-\sum_{\substack{i=J \\ j \neq i \\ j=1}}^{J} \frac{-\beta_{m}}{\exp \left[-\beta_{m} \cdot\left(\chi_{m j q}-\chi_{m i q}\right)\right]+1}\right)+\left[\left(\sum_{\substack{i \in J \\ j \neq i \\ j=1}}^{J} P_{i q} \frac{-\beta_{m}}{\exp \left[-\beta_{k} \cdot\left(\chi_{m j q}-\chi_{m i q}\right)\right]+1}+\right]\right) \cdot \chi_{\substack{i \in J \\ j \neq i \\ j=1}}^{J} P_{j q} \frac{\beta_{m}}{\exp \left[\beta_{m} \cdot\left(\chi_{m j q}-\chi_{m i q}\right)\right]+1}\right)\right]\right)$

e
elasticity of an attribute of the chosen alternative.

As shown in Eq.5 the probability of non-chosen alternative $\left(P_{j q}\right)$ is also influence the In order to account for sampling bias, it is necessary to calculate the aggregate direct point elasticities $\left(E_{i q X_{m i q}}^{W_{i}}\right.$ ) which make sure that the relative change of an attribute to a probability choice is the same for every individual. The measurement formula, presented in Atasoy et al. (33) is shown in Eq. 6.

$$
E_{i q X_{\text {miq }}}^{W_{i}}=\sum_{q=1}^{Q_{s}} E_{i q X_{m i q}} \frac{w_{q} P_{i q}}{\sum_{q=1}^{Q_{s}} w_{q} P_{i q}}
$$

where $w_{q}$ represents the sample weight for an individual $q$ from sample $Q_{s}$ from population $Q$. Each sample on the data set is weighted according to the representation of his/her age and gender category in Jakarta population data set (26).

The aggregate direct point elasticities for all alternatives and all attributes is presented in Table 5. It can be observed that in Model 1 and Model 2, travel time is elastic for public transport, park and ride and car. For the public transport case, it can be interpreted that a $10 \%$ increase in the travel time of public transport, assuming travel time of other three alternatives modes do not change, resulting in a $12 \%$ reduction in probability of choosing public transport.

Overall it can be seen that for Model 1, all attributes are nearly inelastic except for public transport, park and ride, and car travel time. It shows that travel time is an important attribute for choosing those modes. The higher elasticity is for park and ride travel time. The results show that policies to reduce park and ride travel time might increase the probability to choose that mode. As expected, parking cost is nearly inelastic since it is not significant in the model.

Contribution cost seems more influential for car compared to motorcycle. Therefore, applying and increasing contribution cost might actually reduce the probability to choose car. Regarding small effects of the contribution cost, there is a possibility that since the benefit of congestion pricing prior the survey was explained clearly before the survey, car/motorcycle driver might "accept" the benefit of pricing for society. Therefore the higher the congestion pricing might not give a substantial decrease in the probability to choose a car or a motorcycle. 
TABLE 5 Aggregate Direct Point Elasticities

\begin{tabular}{|l|r|r|r|r|}
\hline Attribute & Public transport & Park and ride & Car & Motorcycle \\
\hline Model 1 & -1.273 & -1.445 & -1.358 & -0.731 \\
\hline Travel time & -0.214 & -0.424 & -0.417 & -0.165 \\
\hline Travel cost & -0.165 & -0.200 & NA & NA \\
\hline Waiting time & -0.150 & -0.150 & NA & NA \\
\hline Transfer & NA & NA & -0.406 & -0.138 \\
\hline Contribution cost & NA & -0.054 & -0.077 & -0.029 \\
\hline Parking cost & -1.382 & -1.561 & -1.574 & -0.734 \\
\hline Model 2 & -0.442 & -0.734 & -0.787 & -0.287 \\
\hline Travel time & $7.89 \%$ & $7.43 \%$ & $13.72 \%$ & $0.41 \%$ \\
\hline Travel cost & $51.58 \%$ & $42.23 \%$ & $47.01 \%$ & $42.51 \%$ \\
\hline Model 2 and Model 1 difference
\end{tabular}

The results in Model 2 show that with only two attributes, the travel time of public transport, park and ride, and car are elastic. Those three modes travel cost and also motorcycle travel time are nearly elastic. The high travel time and travel cost for car might be a good sign that to reduce the probability to choose car, it is necessary to implement policy to increase car travel time and travel cost. Overall Model 2 travel time and travel cost elasticities are substantially higher than travel time and travel cost elasticities for Model 1 as shown in the percentage difference.

\section{CONCLUSION}

This paper discusses the influence of the implementation of contribution cost in an arterial road in Jakarta towards Jakartans mode choice decision to pass an arterial road. The method utilized for model estimation in this paper is the recently introduced alternative model called random regret minimization (RRM). In RRM when deciding, an individual is assumed to minimize anticipated regret as opposed to maximizing the utility. The reason to implement RRM is that, paying for contribution cost for private vehicle can lead to a regret of choosing an alternative for example car or motorcycle in comparison to choosing a public transport. This is the first paper that utilized RRM for contribution cost implementation in Jakarta and also the first that presents the calculation of VTTS and demand elasticities based on RRM for Jakarta case.

There are two model estimated for four mode choice alternatives (public transport, park and ride, car, and motorcycle). The first model, Model 1, incorporate all attributes which include travel time, travel cost, waiting time, number of transfer, contribution cost, and parking cost. While the second model, Model 2, only incorporate two attributes travel time and travel cost. All parameters are significant except for parking cost. The insignificant of parking cost might be due to the ease of obtaining parking place and low price of parking. Comparing model fit (rho-square and BIC) it appears that the model fit of Model 2 is substantially higher. The prediction accuracy (hit rate and out of sample hit rate) also show that Model 2 produces higher prediction rate. This might indicate that parsimonious model might resulting better model fit.

The value of travel time savings (VTTS) and contribution cost are also presented. It appears that the incorporation of contribution cost (and other attributes) resulting substantially higher VTTS for Model 1 compares to Model 2. The VTTS of public transport is higher compared to 
other three modes. Higher VTTS for RRM context might also be interpreted as the more individual is willing to pay to minimize regret experienced by choosing that respective mode. Aggregate direct point elasticities for all attributes are also presented. Except for motorcycle, the travel time for other three modes are elastic in Model 1 and Model 2. The contribution cost for car and motorcycle are nearly inelastic, however the contribution cost of car is substantially higher than motorcycle. That means implementing contribution cost and increasing it might influence the probability of choosing car to pass through an arterial road in Jakarta CBD. The small effect of contribution cost might be because the respondents were clearly explained prior the survey about the benefit of contribution cost. Therefore, this would be a positive message, if the respondents have accepted the need for more revenues for public transport/roads improvements.

There are several limitations to this study. The incorporation of only mode choice attributes might not be enough to explain mode choice decision. There are other characteristics such as income, age, gender and perhaps travel distance that can be interacted with the attributes to increase the predictability of the model. The sample selection might also be bias, since it does not closely represent the population as shown in Table 1. For example more than $50 \%$ of the respondents are on school age (below 24). While the young worker age (25-39) is less represented. For aggregate elasticities, the sample weighting might remove that bias, however, more representative samples might be needed. The categorization of income in this study might not be correct since the top category is over-represented. It might be better to start the categorization with the provincial minimum wage as the bottom category. Another shortcomings of this study is regarding the incorporation of psychological aspects that are proven by Sugiarto et al. $(11,12)$ to improve the acceptability of ERP scheme. Therefore, future study might incorporate psychological aspects such as attitudes in RRM context.

\section{REFERENCES}

1. Leung, K. H. Indonesia's Summary Transport Assessment. ADB papers on Indonesia, Vol. 15, 2016. www.adb.org/sites/default/files/publication/217196/ino-paper-15-2016.pdf. Accessed Jul. 25, 2017.

2. Governor of DKI Jakarta Province. Peraturan Gubernur Tentang Kawasan Pengendalian Lalu Lintas [Governor Regulation on Traffic Control Area], Governor Regulation 110/2012, Jakarta, 2012.

3. Anya, A., and D. A. Wardhani. No 3-in-1? Get ready to get stuck in traffic. The Jakarta Post, March 2016. www.thejakartapost.com/news/2016/03/30/no-3-1-get-ready-get-stucktraffic.html. Accessed Jul. 11, 2017.

4. Governor of DKI Jakarta Province. Peraturan Gubernur Tentang Pencabutan Peraturan Gubernur No 110 Tahun 2012 Tentang Kawasan Pengendalian Lalu Lintas [Governor Regulation on the Revocation of Governor Regulation No 110/2012 on Traffic Control Area], Governor Regulation 114/2016, Jakarta, 2016.

5. The Cordinating Ministry of Economic Affairs The Republic of Indonesia, and JICA. Jabodetabek Urban Transportation Policy Integration Project in the Republic of Indonesia. Final Report, 2012.

6. Agarwal, S., and K. M. Koo. Impact of electronic road pricing (ERP) changes on transport modal choice. Regional Science and Urban Economics, Vol. 60, 2016, pp. 1-11. 
7. Santos, G. Urban Congestion Charging: A Comparison between London and Singapore. Transport Reviews, Vol. 25, No. 5, 2005, pp. 511-534.

8. Rotaris, L., D. Romeo, M. Edoardo, and J. Massiani. The urban road pricing scheme to curb pollution in Milan, Italy: Descriptions, impacts, and preliminary cost-benefit analysis assessment. Transportation Research Part A: Policy and Parctice, Vol. 44, No. 5, 2010, pp. 359-375.

9. Eliasson, J., and L.-G. Mattsson. Equity effects of congestion pricing: Quantitative methodology and a case study for Stockholm. Transportation Research Part A: Policy and Parctice, Vol. 40, No. 7, 2006, pp. 602-620.

10. Prayudyanto, M. N., O. Z. Tamin, R. Driejana, and D. Umami. Will Jakarta Road Pricing Reduce Fuel Consumption and Emission? Proceedings of the Eastern Asia Society for Transportation Studies, Vol. 9. 2013.

11. Sugiarto, S., T. Miwa, H. Sato, and T. Morikawa. Use of latent variables representing psychological motivation to explore citizens' intentions with respect to congestion charging reform in Jakarta. Urban, Planning and Transport Research, Vol. 3, No. 1, 2015, pp. 46-67.

12. Sugiarto, S., T. Miwa, H. Sato, and T. Morikawa. Explaining Differences in Acceptance Determinants toward Congestion Charging Policies in Indonesia and Japan. Journal of Urban Planning and Development, Vol. 143, No. 2, 2017.

13. Chorus, C. G. A new model of random regret minimization. European Journal of Transport and Infrastructure Research, Vol. 10, No. 2, 2010, pp. 181-196.

14. Chorus, C. G., T. A. Arentze, and H. J. P. Timmermans. A Random Regret-Minimization model of travel choice. Transportation Research Part B: Methodological, Vol. 42, No. 1, 2008, pp. 1-18.

15. Chorus, C. G. Random Regret Minimization: An Overview of Model Properties and Empirical Evidence. Transport Reviews, Vol. 32, No. 1, 2012, pp. 75-92.

16. Belgiawan, P. F., B. Schmid, I. Dubernet, and K. W. Axhausen. Comparison between RUM, RRM variants, and RAM: Swiss SP and RP data sets. Presented at the $17^{\text {th }}$ Swiss Transport Research Conference (STRC 2017), Monte Verita, Ascona, May 2017, 2017.

17. Hensher, D. A, W. H. Greene, and C. G. Chorus. Random regret minimization or random utility maximization: An exploratory analysis in the context of automobile fuel choice. Journal of Advanced Transportation, Vol. 47, No. 7, 2013, pp. 667-678.

18. Hess, S., M. J. Beck, and C. G. Chorus. Contrast between utility maximisation and regret minimisation in the presence of opt out alternatives. Transportation Research Part A: Policy and Practice, Vol. 66, 2014, pp. 1-12.

19. Chorus, C. G., S. Van Cranenburgh, and T. Dekker. Random regret minimization for consumer choice modelling: Assesment of empirical evidence. Journal of Business Research, Vol. 67, No. 11, 2014, pp. 2428-2436.

20. Leong, W., and D. A. Hensher. Contrast of Relative Advantage Maximisation with Random Utility Maximisation and Regret Minimisation. Journal of Transport Economics and Policy, Vol. 49, No. 1, 2015, pp. 167-186. 
21. Chorus, C. G., and M. Bierlaire. An empirical comparison of travel choice models that capture preferences for compromise alternative. Transportation, Vol. 40, No. 3, 2013, pp. 549-562.

22. Thiene, M., M. Boeri, and C. G. Chorus. Random regret minimization: Exploration of a new choice model for environmental and resource economics. Environmental and Resource Economics, Vol. 51, No. 3, 2012, pp. 413-429.

23. Chorus, C. G. A generalized random regret minimization model. Transportation Research Part B: Methodological, Vol. 68, 2014, pp. 224-238.

24. Van Cranenburgh, S., C. A. Guevara, and C. G. Chorus. New insights on random regret minimisation model. Transportation Research Part A: Policy and Practice, Vol. 74, 2015, pp. 91-109.

25. The Ministry of Transportation The Republic of Indonesia and JICA. Project for the Study on Jabodetabek Public Transportation Policy Implementation Strategy in The Republic of Indonesia (JAPTraPIS). Final Report, Vol. 1, 2012.

26. Governor of DKI Jakarta Province. Peraturan Gubernur Tentang Upah Minimum Provinsi Tahun 2017 [Governor Regulation on the 2017 Provincial Minimum Wage in Jakarta]. Governor Regulation 227/2016, Jakarta, 2016.

27. Statistics of DKI Jakarta Province. Jakarta in Figures 2012. BPS-Statistics of DKI Jakarta Province, 2012.

28. Bierlaire, M. PythonBiogeme: a short introduction. Report TRANSP-OR 160706 Series on Biogeme, Transport and Mobility Laboratory, School of Architecture, Civil and Environmental Engineering, Ecole Polytechnique Fédérale de Lausanne, Lausanne, Switzerland, 2016.

29. Vrtic, M., N. Schuessler, A. Erath, and K. W. Axhausen. The impacts of road pricing on route and mode choice behaviour. Journal of Choice Modelling, Vol. 3, No. 1, 2010, pp. 109126.

30. Belgiawan, P. F., J.-D. Schmöcker and S. Fujii. Understanding car ownership motivations among Indonesian students. International Journal of Sustainable Transportation, Vol. 10, No. 4, 2016, pp. 295-307.

31. Panggabean, R. H. Reclaiming the Streets from Parking Racketeers. Jakarta Globe, September 2014. www.jakartaglobe.id/news/reclaiming-streets-parking-racketeers/. Accessed Jul. 11, 2017.

32. Ben-Akiva, M., and S.R. Lerman. Discrete Choice Analysis: Theory and Application to Travel Demand. MIT Press, Cambridge, 1985.

33. Atasoy, B., A. Glerum, and M. Bierlaire. Attitudes towards mode choice in Switzerland. disP - The Planning Review, Vol. 49, 2013, pp. 101-117. 